Journal of ASTM International, September, 2012, Vol. X No. X

Paper ID: XXXXX

Available online at www.astm.org

\author{
Christina Y. Piña Arpin ${ }^{1}$ and Joel Stoltzfus ${ }^{2}$
}

\title{
Rudimentary Cleaning Compared to Level 300A
}

\begin{abstract}
A study was done to characterize the cleanliness level achievable when using a rudimentary cleaning process, and results were compared to JPR 5322.1G Level 300A. While it is not ideal to clean in a shop environment, some situations (e.g., field combat operations) require oxygen system hardware to be maintained and cleaned to prevent a fire hazard, even though it cannot be sent back to a precision cleaning facility. This study measured the effectiveness of basic shop cleaning. Initially, three items representing parts of an oxygen system were contaminated: a metal plate, valve body, and metal oxygen bottle. The contaminants chosen were those most likely to be introduced to the system during normal use: oil, lubricant, metal shavings/powder, sand, fingerprints, tape, lip balm, and hand lotion. The cleaning process used hot water, soap, various brushes, gaseous nitrogen, water nozzle, plastic trays, scouring pads, and a controlled shop environment. Test subjects were classified into three groups: technical professionals having an appreciation for oxygen hazards; professional precision cleaners; and a group with no previous professional knowledge of oxygen or precision cleaning. Three test subjects were in each group, and each was provided with standard cleaning equipment, a cleaning procedure, and one of each of the three test items to clean. The results indicated that the achievable cleanliness level was independent of the technical knowledge or proficiency of the personnel cleaning the items. Results also showed that achieving a Level 300 particle count was more difficult than achieving a Level A nonvolatile residue amount.
\end{abstract}

KEYWORDS: Precision cleaning, rudimentary cleaning, Level 300, oxygen systems, hardware cleaning procedures, process, non-cleanroom

1 Component Services Project Engineer, Technical Services Office, NASA Johnson Space Center White Sands Test Facility, Las Cruces, New Mexico.

2 Oxygen Group Project Manager, Materials and Components Laboratories Office, NASA Johnson Space Center White Sands Test Facility, Las Cruces, New Mexico. 


\section{Introduction}

Contamination in oxygen enriched environments can act as both a fuel and/or an ignition source. Contamination control is necessary to mitigate risk associated with oxygen systems. One form of contamination control is precision cleaning, in which a value for the level of cleanliness is assigned to specific hardware. In aerospace use, a risk assessment is typically performed to determine the level of cleanliness required to operate a system or hardware safely. Aerospace, unlike other consumers/users of oxygen enriched environments, is typically able to clean and assemble in a certified clean room. The need arose in which equipment used in combat would need to be maintained and cleaned but could not be sent to a precision cleaning facility. While developing cleaning procedures that could be used in the field, two important questions came up: What effect does the personnel cleaning the equipment have on the hardware's end cleanliness level, and what level of cleanliness could be realistically achieved? This study compares three groups of people using rudimentary cleaning techniques to find out what level of cleanliness can be reasonably achieved in a controlled shop environment (an access controlled room with high air flow and sticky mats at each entrance). This study does not compare how different environments will affect the outcome.

\section{Precision Cleaning}

Precision cleaning, as typically performed by NASA White Sands Test Facility (WSTF) in compliance with both ASTM G93 [1] and NASA JPR5322.1G [2], is a three part process. The first part of the process is pre-cleaning, followed by visual inspection, and ending with cleanliness verification. Pre-cleaning is a detailed cleaning performed in a controlled shop environment and utilizes a series of ultrasonic baths which creates implosions that agitate contaminants while the hardware is immersed. Each bath contains either a surfactant, mild 
alkaline, or caustic acid solution. The type of solution used depends on its compatibility with the hardware. Between baths, a technician manually agitates the contaminants on the hardware.

Once the hardware is cleaned, rinsed, and dried using a nitrogen purged oven, it is passed on to another individual for visual inspection. The hardware in the visual inspection area is kept under a downflow unit to maintain its cleanliness. A third party, trained to detect any hardware anomalies, verifies the cleanliness of the hardware using an otoscope and a magnifying fluorescent inspection lamp with a 5-diopter lens. To pass visual inspection, no particles or fibers can be visible, no signs of previous contamination can be detected, and no signs of rust, discoloration or water spots can be seen.

Once the hardware passes visual inspection, it is sent to the ISO (International Organization for Standardization) class 5 clean room for final cleaning and cleanliness verification. This area requires full clean room garments, consisting of coveralls, hood head cover, boot covers, and gloves, to be worn over street clothes at all times. Final cleaning is performed by rinsing the hardware with a solvent. To verify cleanliness of the hardware, a measured amount of the rinse solvent is captured for analysis per ASTM G93-03 solvent extraction test; the rinse solvent is then passed through a membrane filter, which is used to perform the particle count. The solvent is then evaporated, and the remaining nonvolatile residue (NVR) is gravimetrically measured. Precision cleanliness levels are a quantitative measurement, where the count and size of particles are indicated by a number (the smaller the number the cleaner the part) and the amount of NVR per square meter of hardware is indicated by a letter (e.g., "A" is cleaner than "B). The chart in Table 1 describes the cleanliness levels. 


\section{Methodology}

\section{Test Articles}

Three identical sets of hardware were assembled, each containing three items chosen to represent parts of a typical oxygen system: an aluminum plate 6 x 6 x 0.125 in. (15 x 15 x 0.3 cm), a 0.25-in. (0.6-cm) Hoke ${ }^{\circledR 1}$ valve body, and a small oxygen storage bottle (Fig. 1).

\section{Contaminants}

The contaminants chosen were those likely to be introduced to the system during use or be found in a field oxygen shop: oil, lubricant, metal shavings/powder, sand, fingerprints, tape, lip balm, and hand lotion (Fig. 2).

\section{Test Groups}

This study grouped people into one trial group and three test groups of three people each, assembled on a basis of their knowledge and experience of oxygen and contamination control (Table 2). The Trial Group was comprised of three engineers from the WSTF Oxygen Team. For discussion throughout this paper, the Trial Group is not considered one of the test groups, due to changes in the written procedure and changes in test location.

The three test groups represented three sets of knowledge that were of importance in this study. Group 1 was comprised of three clean room technicians with significant experience doing precision cleaning on hardware intended for various applications including oxygen service. Group 2 was comprised of three co-op students who had recently graduated high school; two of them worked as assistants in the WSTF Administrative Department. Group 2 had no prior knowledge of the importance of cleaning hardware for use in oxygen systems. Group 3 was comprised of three engineers from the WSTF Oxygen Team with detailed technical knowledge of the importance of cleaning hardware for oxygen service. Two of the three engineers in this

\footnotetext{
1 Hoke $^{\circledR}$ is a registered trademark of Hoke Incorporated, Spartanburg, SC.
} 
group performed the cleaning process twice, because they had also participated in the Trial Group.

Prior to their cleaning effort, each group was briefed in the procedure and the importance of cleaning hardware for oxygen service. The briefing was similar to that provided to field personnel who would be handling the equipment in question. Each group received a briefing on the cleaning procedure they would be performing.

\section{Equipment}

One important requirement that determined what equipment/tools would be used in the rudimentary cleaning process was the common availability of such equipment to an oxygen field shop. Another consideration was that use of the tools should require minimum training. Groups 1 - 3were supplied with standard cleaning equipment consisting of the following: a set of written procedures; various sizes (diameters of $0.75,0.5$, and 0.375 in. $(1.9,1.3$, and $1.0 \mathrm{~cm})$ ) of stiff black nylon-bristle stainless-steel handle cleaning brushes; a 3-row nylon-bristle Delrin ${ }^{\circledR 1}$ handle cleaning brush; scouring pads; Nitrilite ${ }^{\circledR 2}$ gloves; Kimwipes ${ }^{\circledR 3}$; an otoscope; a fluorescent inspection lamp with a 5-diopter lens; a spray nozzle for $125^{\circ} \mathrm{F}\left(52^{\circ} \mathrm{C}\right)$ hot deionized (DI) water; filtered gaseous nitrogen $\left(\mathrm{GN}_{2}\right)$ at 65 psig $(0.45 \mathrm{mPa})$; and three plastic basins filled with Simple Green ${ }^{\circledR 4}$, water solution, and rinse water. Fig. 3 (cleaning supplies) represents some of the equipment supplied to the groups. The Trial Group had a similar set of supplies with a few substitutions that included tap water in place of DI water, canned air instead of $\mathrm{GN}_{2}$, and a magnifying glass and a flashlight in place of the visual examination tools. HFE 7100 was used in

\footnotetext{
1 Delrin ${ }^{\circledR}$ is a registered trademark of E. I. du Pont de Nemours and company, Wilmington, DE.

2 Nitrilite $^{\circledR}$ is a registered trademark of Ansell Limited, Richmond, Australia.

3 Kimwipes ${ }^{\circledR}$ is a registered trademark of Kimberly-Clark Corporation, Neenah, WI.

4 Simple Green ${ }^{\circledR}$ is a registered trademark of Sunshine Makers, Incorporated, Huntington Beach, CA.
} 
all cases as the verification solvent to determine the level of cleanliness achieved on the hardware using the rudimentary process.

\section{Environment}

The Trial Group used a preliminary version of the procedure for which they set up their own cleaning process in a room equipped only with a stainless steel sink, domestic hot water, and a table-top surface on which to work. For the actual testing, Groups 1 through 3 were set up on a stainless steel work top in the WSTF pre-clean room, which is a controlled shop environment with a higher than normal exchange of air and sticky mats at each entrance; only a smock is worn over street clothes in this area.

\section{Test article contamination}

Before the study began, each type of test article was uniformly contaminated following the procedures detailed in Table 3.

\section{Recommended Rudimentary Procedures}

Identical recommended procedures, presented as follows, were supplied to the three test groups. (Note that any mention of inspection is not an official visual inspection by a third party.) 
Equipment

Water-

Brushes-

Soap-

Gloves-

Rags-

Inspection

Tools-

Work Surface

and Washing

Station-
Hot DI water, with a high pressure wand or nozzle. If DI water is not available, use the cleanest available water supply.

Note: In all cases, warmer and cleaner water is better. If gloves can be worn to enable the water temperature to be higher, that is a favorable practice. Warm or hot water cuts grease and dissolves oil deposits far better than cool or cold water.

Metal pans to contain cleaning solutions and rinse water. If metal pans are not available, plastic pans may be used.

Clean brushes in a variety of sizes and shapes to fit small crevices and reach all ends (e.g., spiral brush, end brush, bottle brushes, toothbrush-style brush), nonmetallic scouring pads.

Warning: Ensure that the brushes will not damage the hardware to be cleaned. Warning: Do not use metallic scouring pads because they shed particles that can either rust or become imbedded in softer materials, or both.

Note: Brush or tool extensions can be fabricated, if necessary, to enable physical scrubbing of parts that are otherwise inaccessible.

Soap with no moisturizers or scents added (e.g., Simple Green). If unavailable, use dish soap.

Nylon gloves that tend not to shed particulate. If non-shedding gloves are not available, use rubber gloves.

Lint free cloth or paper wipes (e.g., Kimwipes), cotton cloth

Magnifying glass, flashlight, otoscope (can be used for looking inside vessels and components), fluorescent lamp with magnifying glass, bright light source

Work surface and washing station that are located near one another Metal surface that can be wiped clean or a visually clean plastic or paper sheet to cover work surface

Note: The work surface will be used to locate items that must be kept clean during the process such as clean brushes, wipes, bags, and gloves, as well as provide a location that clean items can be located while preparing for bagging after the cleaning process is complete. Finally, the work surface will be used for disassembly and re-assembly of components. 
General Procedure

Prepare Choose a work area that is somewhat controlled to avoid open access and to Workplace - minimize contamination. Get all supplies and tools together before beginning the cleaning process to avoid delays once the cleaning process is underway.

Wipe down the metal work surface or place a clean plastic sheet or clean paper on the work surface.

- Ensure that the work surface remains visually clean during the disassembly and cleaning processes.

- If necessary, wipe down the work surface to ensure that contamination from one item does not get transferred to other items.

Set up a series of wash/rinse pans.

- Wash pans should progress from less to more clean.

- For example, the first pan might contain hot, soapy water for pre-cleaning and soaking dirtier items. The second pan might contain hot, soapy water for scrubbing cleaner items. The third pan might be for initial rinsing, and the fourth pan might contain clean, hot water for final rinsing.

- Change out the water in each pan as required when it becomes dirty.

Disassemble - Completely disassemble the component so that all crevices and internal surfaces are as accessible as possible.

Note: Each part must be cleaned separately, in a disassembled configuration. If they are not, the effectiveness of the cleaning procedure will be significantly reduced. Parts that are not removed provide crevices and cracks that will retain contaminants and it will not be possible to clean the adjoining surfaces of the parts.

Pre-clean- Remove excessive contamination.

- Wipe the component.

- Discard the soiled wipes.

- Continue this process until as much visible contamination is removed as possible. 
Wash - Soak item in hot (the hotter, the better) soapy water as needed to loosen contaminant from surfaces.

- If item is a tank or a bottle, fill it with soapy water until it is overflowing, then let it soak.

Scrub/agitate the part thoroughly.

- Use brushes, wetted Kimwipes, or cotton cloth.

- Pay special attention to threads, crevices, and hidden surfaces that, because of their configuration, can trap contaminants.

- If internal surfaces cannot be scrubbed mechanically, then spray the inaccessible areas. If scrubbing or spraying are not possible, fill the item with hot, soapy water, plug the holes, and shake it vigorously.

Note: Ensure that many suds are formed during the washing process; if there are few suds, then add more water and soap. If suds don't form, it indicates that the all the oil contamination is not captured by the surfactant.

- Change the wash water, add soap, and repeat the washing process twice for a total of three washes.

Note: This procedure amounts to very rigorous dishwashing with very careful attention given to detail and precision. The hotter and soapier the water the better. The repetitions ensure that the surface is thoroughly cleaned and that layered contamination is wetted, agitated, and removed.

Rinse- $\quad$ Rinse item thoroughly to remove soap and contaminant.

- Dunk and spray item with clean hot water as needed to remove all visible residues.

- If item is a bottle, then fill, shake, and empty the water until no suds are left and the water coming out is as clear as water going in.

Note: Nylon gloves should be rinsed often to remove contaminants and particles obtained by touching contaminated parts. If a particle can be transferred to a cleaned part by physical contact, it is very likely that it can be rinsed off. Rinse it off prior to touching the parts.

Inspect rinse water.

- Catch the last rinse water in clear container.

- Look for particles or grease in the water using a magnifying glass and by shining a bright white light through the water

- If no particles are present or grease is observed on the surface (as a colorful sheen) and the water is as clear as it was from the source, move on to drying; if not, repeat the wash and rinse steps.

Note: When washing carbon steel components like the oxygen bottles, perform the final rinse with cold water and then dry immediately. The combined effects of cooling the carbon steel surface and drying it quickly will inhibit as much as possible the formation of rust. 

Dry- Blow dry.
- Use oil-free, filtered $\mathrm{GN}_{2}$ or air if available.
- If filtered gasses are not available, use filtered compressed or canned air.
Note: It is preferable to dry parts quickly, removing all water droplets, to avoid deposits of water-borne contaminants (water spots).
Air dry.
- $\quad$ Set aside in a clean, isolated area to air dry.
Wipe dry.
- If water droplets remain, they can be carefully removed using clean, folded Kimwipes
Inspect- Inspect item to verify cleanliness.
- Visually inspect, using magnification if available, all surfaces using the most intense light available.
- Take care to inspect small crevasses, threads, and holes.
- If any discoloration, water deposits, soap residue, or particulate are observed, remove it. If necessary, repeat the wash and rinse steps.

\section{Experimental Procedure}

Once the test articles and contaminants were selected, the test articles were visually examined to ensure they were at a similar level of cleanliness and to note the initial condition of the test articles. (This visual examination should not be confused as an official visual inspection as identified earlier in the precision cleaning area of this paper.) The test articles were then contaminated. Each piece from the three hardware sets were contaminated using the process outlined in Table 3, so that each test group started with hardware that was similarly soiled when they began the cleaning process.

The three individuals in each test group were provided with a set of identical cleaning supplies and a set of contaminated test articles. Each individual cleaned their three items following the recommended cleaning process and using only the supplied set of tools. Once the individual declared their test articles to be cleaned, the test articles were sampled using HFE 7100 by a WSTF clean room technician (not in a test group) to measure the amount of particulate and NVR. This process was repeated for each individual in the three test groups. 


\section{Sample Collection}

To determine the cleanliness level of the hardware, a verification process similar to what is performed in the precision cleaning process was performed in the WSTF pre-clean room using a 40 - to 60 -psig (0.3- to $0.4-\mathrm{mPa})$ rated pressure vessel. The pre-clean room location was chosen due to concerns about contaminating the WSTF ISO class 5 clean room by taking in hardware that had only gone through a rudimentary cleaning process. A clean room technician flushed each test article with $100 \mathrm{~mL}$ of HFE 7100, which was collected and filtered through a $0.45-\mu \mathrm{m}$ membrane filter. The membrane and the remaining HFE 7100 sample were sent to the WSTF chemistry lab for particle count and NVR analysis. Analysis of Data

The results were compared to the cleanliness requirements for Level 300A as defined by NASA JPR 5322.1G. As described in Table 1, Level 300 is defined as 0 particles $>300 \mu \mathrm{m}$, 3 particles from 250 to $300 \mu \mathrm{m}, 93$ particles from 100 to $250 \mu \mathrm{m}$, and no limit on particles $<100 \mu \mathrm{m}$; no silting is allowed. NVR Level A is defined as $1.0 \mathrm{mg} / \mathrm{m}^{2}$ or less. Both of these cleanliness parameters are adequate to reduce the fire hazards in the subject oxygen system. To further simplify and unify analysis of the data, each part of the cleanliness level (the particle count and the NVR) was seen as a parameter to be met. The parameters were met on pass/fail criteria, so if the cleanliness level of hardware was measured to be a 200A, for example, that meant it passed the two parameters for that test article. If, however, the verification resulted in a 300B or >300A, both cases would only have passed one of the two parameters: the level 300B would have passed the particle count parameter, but failed the NVR parameter; and the level > 300A would have failed the particle count parameter, but passed the NVR parameter. 
Due to the complexity of measuring and comparing cleanliness of hardware, this study mainly focused on the quantitative analysis of cleanliness. The visual inspection pass/fail parameters normal for precision cleaning were not considered in this study. Additionally the ratio of test parameters met/needed to be met in order for the hardware to pass a Level 300A was used to compare the performance of the three test groups. For example, Group 1 had three people, each person had three test articles, and two cleanliness parameters needed to be met on each test article. This means that Group 1 had 18 cleanliness parameters to meet. However, if the group only reached a Level 300 or better three times and a level A eight times, that means they met 11/18 of the parameters (referred to as the ratio of parameters passed).

\section{Results and Discussion:}

Table 4 shows the level of cleanliness reached by each individual in each of the groups. Each of the groups met nearly identical numbers of the Level 300A cleanliness parameters (see Table 5). This suggests that the results obtained are not dependent upon the age, experience, technical training, or prior knowledge of oxygen hazards. The results indicate that the instructions are adequate to produce a very consistent result, and special training does not produce improved cleaning results.

It is also apparent that the NVR levels were met much more frequently than the particulate levels. The ratio of parameters met for the plate, valve body, and bottle NVR levels were $9 / 9,9 / 9$, and $7 / 9$ respectively, whereas the ratio of parameters met for the particle levels were 2/9, 3/9, and 4/9 respectively. Only 33 percent of the particulate samples passed Level 300 compared to nearly 93 percent of the NVR samples. This implies that it is much easier to remove the NVR (which includes substances like oil, lip balm, Krytox ${ }^{\circledR 1}$ lubricant, and

\footnotetext{
1 Krytox $^{\circledR}$ is a registered trademark of E. I. du Pont de Nemours and Company, Wilmington, DE.
} 
fingerprints) than it is to remove and control the particulate contaminant (which includes items like particles and fibers).

The tendency to meet the NVR requirement but not meet the particulate requirement was very consistent between groups, suggesting that the efficacy of the procedure is relatively independent of increased prior knowledge of oxygen hazards, cleaning experience, and advanced education of the person doing the cleaning.

Due to their availability, the brushes used for cleaning were clean room brushes. These brushes are specially designed to shed few particles and bristles, and it is not known what the effect of other (non clean room) brushes would be on the recommended rudimentary field procedure.

The oxygen bottle was the most difficult item from which to remove the NVR. Compared to the plate and the valve body, for which 11/12 and 12/12 parameters passed the Level A specification, the vessel passed less frequently (i.e., 9/12 times). This leads to the conclusion that special training emphasis should be placed on how to clean the inside of the bottle. The vessel also showed signs of rust after the Trial Group cleaned it, and the other groups as well. This was not a surprise, since water was used to clean the vessel and water would cause flash rusting. However, it does lead to concerns as to whether or not the vessel can be considered to have passed the 300A level cleanliness parameters, because even if it met the analytical parameters, the vessel did not meet a visual inspection-which is a precursor to any analytical verification of cleanliness. If this vessel had gone through the standard precision cleaning process, the rust in the vessel would have needed to be mitigated before any verification sample was collected. It is worth noting that the solvent used to verify cleanliness was HFE 7100, which is not a very aggressive solvent and not normally used to validate a cleaning processes. HFE 7100 is typically 
used as part of a cleaning process to verify the cleanliness of the parts once the process as a whole has been validated. A more aggressive solvent such as AK225 is recommended to validate a cleaning process. However, HFE 7100 was chosen due to its accessibility and the equipment configurations that were available.

The possible lack of control of the particulate contaminant and the presence of rust increase the possibility of a particle impact ignition mechanism being present in such an oxygen system. An evaluation of the possibility of particle impact ignition in the subject oxygen system was recommended to ensure that a credible fire hazard did not exist. If particles too few or too small exist after the cleaning process to produce a credible particle impact ignition source, the cleaning process tested in this paper could be used to maintain this oxygen system. The cleaning process tested in this paper could be used to maintain oxygen systems if it were determined that this process produced particles too few or too small to create a credible particle impact ignition source.

\section{Conclusion}

With proper cleaning procedures that incorporate contamination control principles, a cleanliness level of 300A is possible to quantitatively achieve in a field shop environment. However, the consistency of cleanliness parameters met cannot compare to those achieved in a production precision cleaning facility. With the joint understanding of oxygen and contamination control, one can determine if such field cleaning can meet the requirements to maintain a safe oxygen system. 


\section{References}

[1] ASTM G93. Standard Practice for Cleaning Methods and Cleanliness Levels for Material and Equipment Used in Oxygen-Enriched Environments. American Society for Testing and Materials, West Conshohocken, PA, 2003.

[2] NASA JPR5322.1G. Contamination Control Requirements Manual. NASA Johnson Space Center Procedural Requirements. Houston, TX, 2009. 
TABLE 1-Cleanliness levels (per NASA JPR 5322.1G).

\begin{tabular}{|c|c|c|c|c|c|c|c|c|}
\hline \multirow{2}{*}{$\begin{array}{c}\text { What is } \\
\text { Measured }\end{array}$} & \multirow[t]{2}{*}{ Units } & \multirow{2}{*}{$\begin{array}{c}\text { Comparable } \\
\text { to: }\end{array}$} & \multirow{2}{*}{$\begin{array}{r}\text { Level } \\
300\end{array}$} & \multicolumn{5}{|c|}{ Requirements to Pass } \\
\hline & & & & Range $(\mu \mathrm{m})$ & $<100$ & $100-250$ & $250-300$ & $>300$ \\
\hline \multirow{5}{*}{$\begin{array}{l}\text { Number of } \\
\text { particles \& } \\
\text { size of } \\
\text { particles }\end{array}$} & \multirow{5}{*}{$\begin{array}{l}\text { Particles \& } \\
\text { micrometers } \\
(\mu)\end{array}$} & \multirow{5}{*}{$\begin{array}{l}\text { Human hair } \\
=50 \text { to } 120 \mu\end{array}$} & & Max allow count & unlimited & 93 & 3 & 0 \\
\hline & & & 200 & Range $(\mu \mathrm{m})$ & $<50$ & $50-100$ & $101-200$ & $>200$ \\
\hline & & & & Max allow count & unlimited & 154 & 16 & 0 \\
\hline & & & 100 & Range $(\mu \mathrm{m})$ & $<25$ & $25-50$ & $51-100$ & $>100$ \\
\hline & & & & Max allow count & unlimited & 68 & 11 & 0 \\
\hline \multirow{4}{*}{$\begin{array}{l}\text { Nonvolatile } \\
\text { residue } \\
\text { (oils, } \\
\text { grease) }\end{array}$} & \multirow{4}{*}{$\begin{array}{l}\text { miligrams } \\
(\mathrm{mg})\end{array}$} & \multirow{4}{*}{$\begin{array}{l}\text { Feather } \\
\approx 1 \mathrm{mg}\end{array}$} & A & $<1 \mathrm{mg} / \mathrm{m}^{2}$ & & & & \\
\hline & & & B & $<2 \mathrm{mg} / \mathrm{m}^{2}$ & & & & \\
\hline & & & $\mathrm{C}$ & $<3 \mathrm{mg} / \mathrm{m}^{2}$ & & & & \\
\hline & & & $\mathrm{D}$ & $<4 \mathrm{mg} / \mathrm{m}^{2}$ & & & & \\
\hline
\end{tabular}

TABLE 2- Test groups.

\begin{tabular}{|c|c|c|}
\hline Group name & $\begin{array}{c}\text { Group Member } \\
\text { discription and ID \# }\end{array}$ & Group Discription \\
\hline Trial Group & $\begin{array}{l}\text { Engineer } 1 \\
\text { Engineer } 2 \\
\text { Engineer } 3\end{array}$ & $\begin{array}{l}\text { Followed a procedure \#1 and performed } \\
\text { cleaning in a non controlled environment. }\end{array}$ \\
\hline Test Group 1 & $\begin{array}{l}\text { Cleaning technician } 1 \\
\text { Cleaning technician } 2 \\
\text { Cleaning technician } 3\end{array}$ & \multirow{3}{*}{$\begin{array}{l}\text { Followed a procedure \#2 and performed } \\
\text { cleaning in a controlled shop environment. }\end{array}$} \\
\hline Test Group 2 & $\begin{array}{l}\text { Co-op student } 1 \\
\text { Co-op student } 2 \\
\text { Co-op student } 3\end{array}$ & \\
\hline Test Group 3 & $\begin{array}{l}\text { Engineer } 1 \\
\text { Engineer2 } \\
\text { Engineer } 4\end{array}$ & \\
\hline
\end{tabular}


TABLE 3-Contamination process.

\begin{tabular}{|c|c|c|}
\hline Test Article & & Steps taken for Contamination of Test Articles \\
\hline Plates: & $\begin{array}{l}1 \\
2 \\
3 \\
4 \\
5 \\
6 \\
7 \\
8\end{array}$ & $\begin{array}{l}\text { Initial condition: Shear-break edges, no special protection, visually similar } \\
\text { Fingerprints: Flip \& grip } 10 \text { times per each of } 5 \text { people } \\
\text { Lip balm: Smear on ( one long swipe on both sides near edge A) } \\
\text { Krytox }{ }^{\circledR} \text { lubricant: Dab \& smear ( one long swipe on both sides near edge B) } \\
\text { Lotion: Small dab \& smear (one long swipe on both sides near edge C) } \\
\text { Oil: } 3 \text { drops \& smear (one long swipe on both sides near edge D) } \\
\text { Metal powder: Dust (like salt) entire surface } \\
\text { Sand: Dust (like salt) entire surface } \\
\text { Bag (unsealed) }\end{array}$ \\
\hline $\begin{array}{c}\text { Oxygen } \\
\text { Bottle }\end{array}$ & $\begin{array}{l}1 \\
2 \\
3 \\
4 \\
5\end{array}$ & $\begin{array}{l}\text { Initial condition: As received from customer, uncapped, no gross } \\
\text { contamination, oil residue on threads. After first cleaning some rust was seen } \\
\text { in bottle } \\
\text { Krytox }{ }^{\circledR} \text { lubricant: Small dab on threads, insert/remove fitting } \\
\text { Oil: } 5 \text { drops inside (from last thread to drip into bottle) } \\
\text { Metal powder: Drop } 1 \text { spatula of powder inside \& shake } \\
\text { Sand: Drop } 1 \text { spatula of sand inside and shake } \\
\text { Bag ( unsealed) }\end{array}$ \\
\hline Valve & $\begin{array}{l}1 \\
2 \\
3 \\
4 \\
5 \\
6 \\
7\end{array}$ & $\begin{array}{l}\text { Initial condition: Cleaned 200A , opened, disassembled } \\
\text { Fingerprints: Flip \& grip } 10 \text { times per each of } 5 \text { people } \\
\text { Krytox }{ }^{\circledR} \text { lubricant: Lube initial parts, reinsert and remove } \\
\text { Oil: } 3 \text { drops and shake } \\
\text { Metal powder: Drop } \sim 2 \mathrm{~mL} \text { of powder inside and shake } \\
\text { Sand: Drop } \sim 2 \mathrm{~mL} \text { of sand inside and shake } \\
\text { Teflon tape: Wrap threads with Teflon tape, insert and remove fitting } \\
\text { Bag (unsealed) }\end{array}$ \\
\hline
\end{tabular}


TABLE 4-Test results showing particulate and NVR levels achieved.

\begin{tabular}{ccccccc}
\hline \multirow{2}{*}{ Group } & \multicolumn{3}{c}{ Plate: } & \multicolumn{2}{c}{ Valve Body } & \multicolumn{2}{c}{ Oxygen Bottle } \\
\cline { 2 - 6 } Trial Group & Particle & NVR & Particle & NVR & Particle & NVR \\
& $>300$ & B & $>300$ & A & 200 & $>$ D \\
& 200 & A & 100 & A & $>300$ & A \\
\hline Test Group 1 & $>300$ & A & 200 & A & $>300$ & A \\
& $>300$ & A & 200 & A & 300 & A \\
& $>300$ & A & $>300$ & A & $>300$ & $>$ D \\
\hline Test Group 2 & $>300$ & A & $>300$ & A & 300 & A \\
& $>300$ & A & 300 & A & $>300$ & A \\
& $>300$ & A & $>300$ & A & 300 & A \\
\hline Test Group 3 & $>300$ & A & 300 & A & $>300$ & A \\
& 200 & A & $>300$ & A & $>300$ & A \\
& 300 & A & $>300$ & A & $>300$ & B \\
\hline
\end{tabular}

TABLE 5-Ratio of parameters passed to achieve Level 300A cleanliness.

\begin{tabular}{lccccccc}
\hline \multirow{2}{*}{ Group } & \multicolumn{3}{c}{ Plate } & \multicolumn{2}{c}{ Valve Body } & Oxygen Bottle & Group \\
& Particle & NVR & Particle & NVR & Particle & NVR & Ratio \\
\hline $\begin{array}{l}\text { Trial Group } \\
\text { (Engineers) }\end{array}$ & $2 / 3$ & $2 / 3$ & $2 / 3$ & $3 / 3$ & $1 / 3$ & $2 / 3$ & $12 / 18$ \\
$\begin{array}{l}\text { Test Group 1 } \\
\text { (Cleaning technicians) }\end{array}$ & $0 / 3$ & $3 / 3$ & $1 / 3$ & $3 / 3$ & $2 / 3$ & $2 / 3$ & $11 / 18$ \\
$\begin{array}{l}\text { Test Group 2 } \\
\text { (Co-op Students) }\end{array}$ & $0 / 3$ & $3 / 3$ & $1 / 3$ & $3 / 3$ & $2 / 3$ & $3 / 3$ & $12 / 18$ \\
$\begin{array}{l}\text { Test Group 3 } \\
\text { (Engineers) }\end{array}$ & $2 / 3$ & $3 / 3$ & $1 / 3$ & $3 / 3$ & $0 / 3$ & $2 / 3$ & $11 / 18$ \\
All Groups: & $4 / 12$ & $11 / 12$ & $5 / 12$ & $12 / 12$ & $5 / 12$ & $9 / 12$ & \\
Test Groups only: & $2 / 9$ & $9 / 9$ & $3 / 9$ & $9 / 9$ & $4 / 9$ & $7 / 9$ & \\
\hline
\end{tabular}




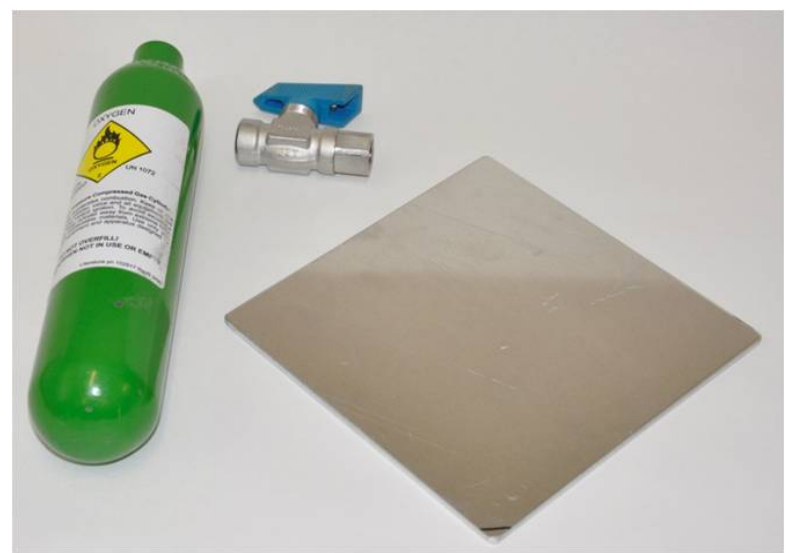

FIG. 1-Test articles representing parts of the oxygen system.

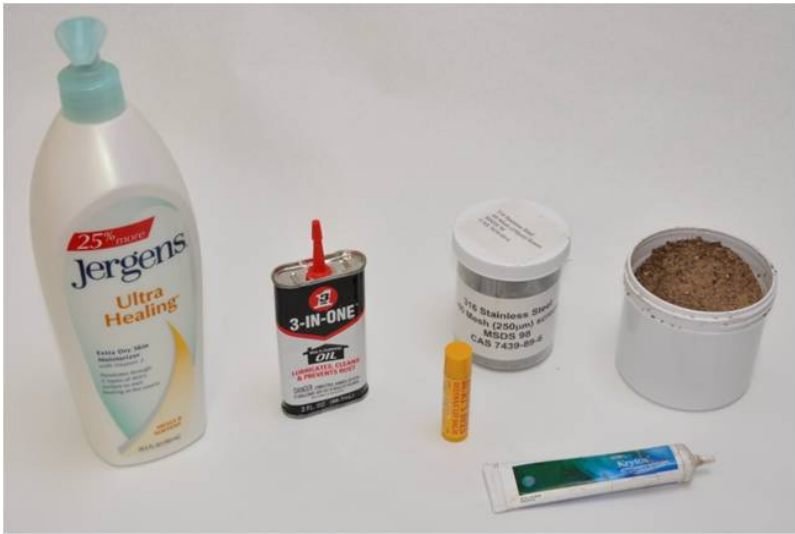

FIG. 2- Contaminants were chosen for likelihood to be used in the field.

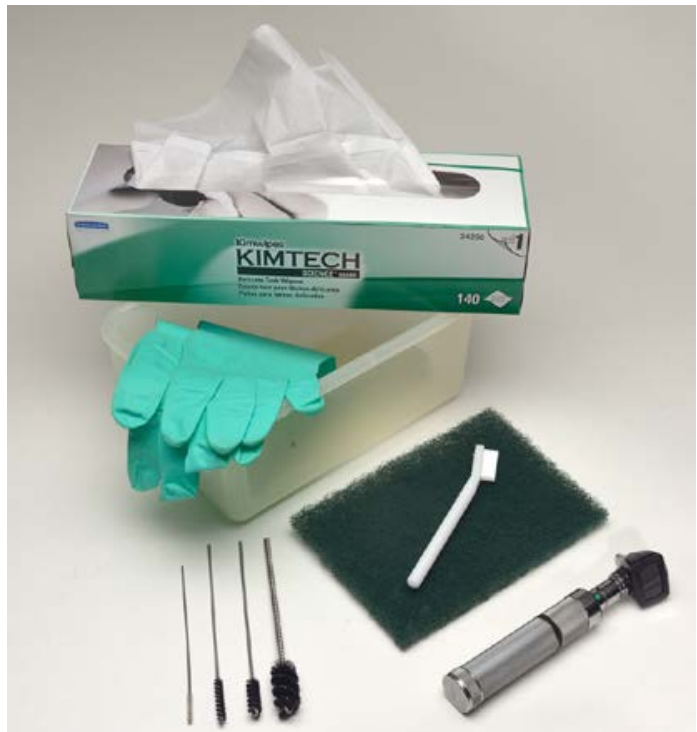

FIG. 3- Cleaning supplies and tools. 


\section{Rudimentary Cleaning Compared to Level 300A}

Christina Y. Piña Arpin and Joel Stoltzfus NASA Johnson Space Center White Sands Test Facility 


\section{Introduction}

- Contamination control is critical to mitigate risks of ignition in oxygen enriched environments.

- Oxygen system hardware must be cleaned and maintained to prevent a fire hazard.

- Some situations, such as field combat operations, do not allow sending hardware to a precision cleaning facility.

- This study measured the effectiveness of basic, rudimentary shop cleaning compared to Level 300A. 


\section{Introduction (cont'd)}

- While developing cleaning procedures that could be used in the field, two important questions came up:

- What effect does the personnel cleaning the equipment have on the hardware's end cleanliness level?

- What level of cleanliness could be realistically achieved?

- This study compares three groups of people using rudimentary cleaning techniques to find out what level of cleanliness can be reasonably achieved in a controlled shop environment (an access controlled room with high air flow and sticky mats at each entrance).

- Environmental conditions were not considered in this study. 


\section{Precision Cleaning}

- Precision cleaning, as typically performed by NASA White Sands Test Facility (WSTF) in compliance with both ASTM G93 and NASA JPR5322.1G, is a three part process:

- Pre-cleaning

- Visual inspection

- Cleanliness verification 


\section{Precision Cleaning (cont'd)}

- Pre-cleaning

- Detailed cleaning is performed in a controlled shop environment.

- A series of ultrasonic baths create implosions to agitate contaminants on immersed hardware.

- Hardware-compatible solutions used are either surfactant, mild alkaline, or caustic acid.

- Hardware contaminants are manually agitated between baths.

- Hardware is dried using a nitrogen-purged oven.

- Hardware is passed on to another individual for visual inspection. 


\section{Precision Cleaning (cont'd)}

- Visual Inspection

- Hardware is kept under a downflow unit to maintain its cleanliness.

- Cleanliness Verification

- A third person, trained to detect hardware anomalies, verifies the hardware cleanliness.

- Inspection uses an otoscope and magnifying fluorescent inspection lamp with 5-diopter lens.

- No particles/fibers can be visible, nor signs of rust, discoloration, or water spots.

- After passing visual inspection, hardware is sent to ISO Class 5 clean room for final cleaning and cleanliness verification. 


\section{Precision Cleaning (cont'd)}

- Class 5 Clean Room

- Full clean-room garments (coveralls, head hood and boot covers, gloves) are used.

- Final cleaning is with a solvent rinse.

- Cleanliness verification

- Rinse solvent is captured for analysis per ASTM G93-03.

- Rinse solvent is strained through membrane filter for particle count (ASTM F312-08).

- Solvent is evaporated, and the remaining nonvolatile residue (NVR) is gravimetrically measured (ASTM F331-05). 


\section{Precision Cleaning (cont'd)}

- Precision Cleanliness Levels

- Quantitative measurement

- The count and size of particles are given a number (the smaller the number the cleaner the part).

- The amount of NVR per square meter of hardware is given a letter (e.g., "A" is cleaner than "B").

- Assignment of particle size/count numbers and NVR letters is specified by NASA JPR 5322.1G, as shown in Table 1. 


\section{Precision Cleaning (cont'd)}

TABLE 1-Cleanliness levels (per NASA JPR 5322.1G).

\begin{tabular}{|c|c|c|c|c|c|c|c|c|}
\hline What is & Units & Comparable & Level & & Requiremer & S to Pass: & & \\
\hline \multirow{6}{*}{$\begin{array}{l}\text { Number of } \\
\text { particles \& } \\
\text { size of } \\
\text { particles }\end{array}$} & \multirow{6}{*}{$\begin{array}{l}\text { Particles \& } \\
\text { micrometers } \\
(\mu \mathrm{m})\end{array}$} & \multirow{6}{*}{$\begin{array}{l}\text { Human hair } \\
=50 \text { to } 120 \mu\end{array}$} & 300 & Range $(\mu \mathrm{m})$ & $<100$ & $100-250$ & $250-300$ & $>300$ \\
\hline & & & & Max allow count & unlimited & 93 & 3 & 0 \\
\hline & & & 200 & Range $(\mu \mathrm{m})$ & $<50$ & $50-100$ & $101-200$ & $>200$ \\
\hline & & & & Max allow count & unlimited & 154 & 16 & 0 \\
\hline & & & 100 & Range $(\mu \mathrm{m})$ & $<25$ & $25-50$ & $51-100$ & $>100$ \\
\hline & & & & Max allow count & unlimited & 68 & 11 & 0 \\
\hline \multirow{4}{*}{$\begin{array}{l}\text { Nonvolatile } \\
\text { residue } \\
\text { (oils, } \\
\text { grease) }\end{array}$} & \multirow{4}{*}{$\begin{array}{l}\text { milligrams } \\
(\mathrm{mg})\end{array}$} & \multirow{4}{*}{$\begin{array}{l}\text { Feather } \\
\approx 1 \mathrm{mg}\end{array}$} & A & $<1 \mathrm{mg} / \mathrm{m}^{2}$ & & & & \\
\hline & & & B & $<2 \mathrm{mg} / \mathrm{m}^{2}$ & & & & \\
\hline & & & $\mathrm{C}$ & $<3 \mathrm{mg} / \mathrm{m}^{2}$ & & & & \\
\hline & & & $\mathrm{D}$ & $<4 \mathrm{mg} / \mathrm{m}^{2}$ & & & & \\
\hline
\end{tabular}




\section{Methodology}

- Test Articles

- Three identical sets of three items were chosen to represent parts of a typical oxygen system:

- Aluminum plate, $6 \times 6 \times 0.125$ in. $(15 \times 15 \times 0.13 \mathrm{~cm})$

- Cast stainless steel (SS) ball valve body, 0.25 in. $(0.6 \mathrm{~cm})$

- Small oxygen storage bottle

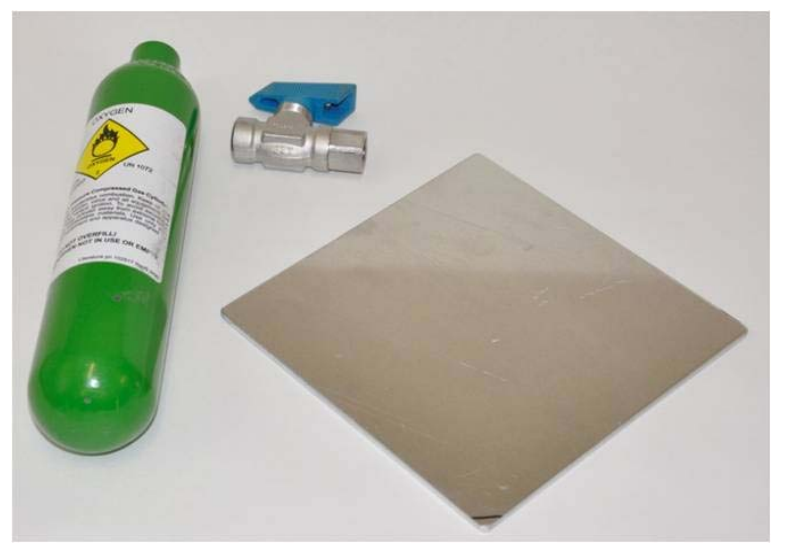




\section{Methodology (cont'd)}

- Contaminants

- Contaminants chosen were representative of materials that could contaminate the system during use or be found in a field shop:

- Oil

- Lubricant

- Metal shavings/powder

- Sand

- Fingerprints

- Tape

- Lip balm

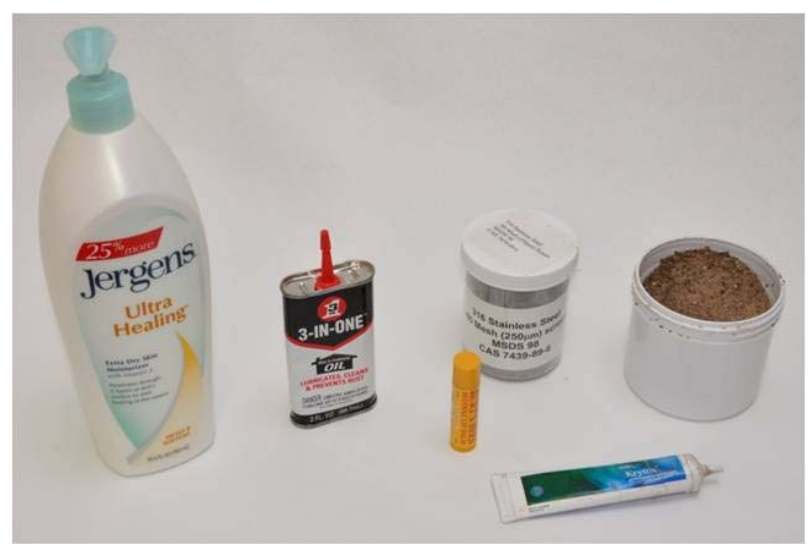

- Hand lotion 


\section{Methodology (cont'd)}

- Test Groups of 3 people each (see Table 2)

- Trial group: Engineers from the WSTF Oxygen Team

- The Trial Group is not considered one of the test groups due to changes in the written procedure and test location.

- Three test groups: Represented three sets of knowledge

- Group 1 - Clean room technicians

- Group 2 - Co-op students, no prior knowledge of cleaning oxygen system hardware

- Group 3 - WSTF Oxygen Team engineers with detailed technical knowledge of the importance of cleaning hardware for oxygen service (Two of these three had also participated in the Trial Group.)

- Each group received a briefing on the cleaning procedure, similar to that for field personnel. 


\section{Methodology (cont'd)}

TABLE 2-Test groups.

\begin{tabular}{|c|c|c|}
\hline Group name & $\begin{array}{c}\text { Group Member } \\
\text { description and ID \# }\end{array}$ & Group Description \\
\hline Trial Group & $\begin{array}{l}\text { Engineer } 1 \\
\text { Engineer } 2 \\
\text { Engineer } 3\end{array}$ & $\begin{array}{l}\text { Followed a procedure } \# 1 \text { and performed } \\
\text { cleaning in a non-controlled environment. }\end{array}$ \\
\hline Test Group 1 & $\begin{array}{l}\text { Cleaning technician } 1 \\
\text { Cleaning technician } 2 \\
\text { Cleaning technician } 3\end{array}$ & \multirow{3}{*}{$\begin{array}{l}\text { Followed a procedure } \# 2 \text { and performed } \\
\text { cleaning in a controlled shop environment. }\end{array}$} \\
\hline Test Group 2 & $\begin{array}{l}\text { Co-op student } 1 \\
\text { Co-op student } 2 \\
\text { Co-op student } 3 \\
\end{array}$ & \\
\hline Test Group 3 & $\begin{array}{l}\text { Engineer } 1 \\
\text { Engineer2 } \\
\text { Engineer } 4\end{array}$ & \\
\hline
\end{tabular}




\section{Methodology (cont'd)}

- Equipment

- Items are those commonly available in an oxygen field shop.

- Use of items requires minimum training.

- Test Groups 1 - 3 were supplied with the following:

- Set of written procedures

- Stiff black nylon-bristle SS-handle cleaning brushes, various sizes (diameters $0.75,0.5$, and 0.375 in. $(1.9,1.3$, and $1.0 \mathrm{~cm})$

- A 3-row nylon bristle Delrin ${ }^{\circledR}$ handle cleaning brush

- Scouring pads, Nitrilite ${ }^{\circledR}$ gloves, and lint free wipes (Kimwipes ${ }^{\circledR}$ )

- Otoscope

- Fluorescent inspection lamp with 5-diopter lens

- Spray nozzle for $125^{\circ} \mathrm{F}\left(52^{\circ} \mathrm{C}\right)$ hot deionized (DI) water

- Filtered gaseous nitrogen at $65 \mathrm{psig}(0.45 \mathrm{mPa})$

- Three plastic basins filled with aqueous degreaser (Simple Green ${ }^{\circledR}$ ) 


\section{Methodology (cont'd)}

Cleaning Supplies and Tools

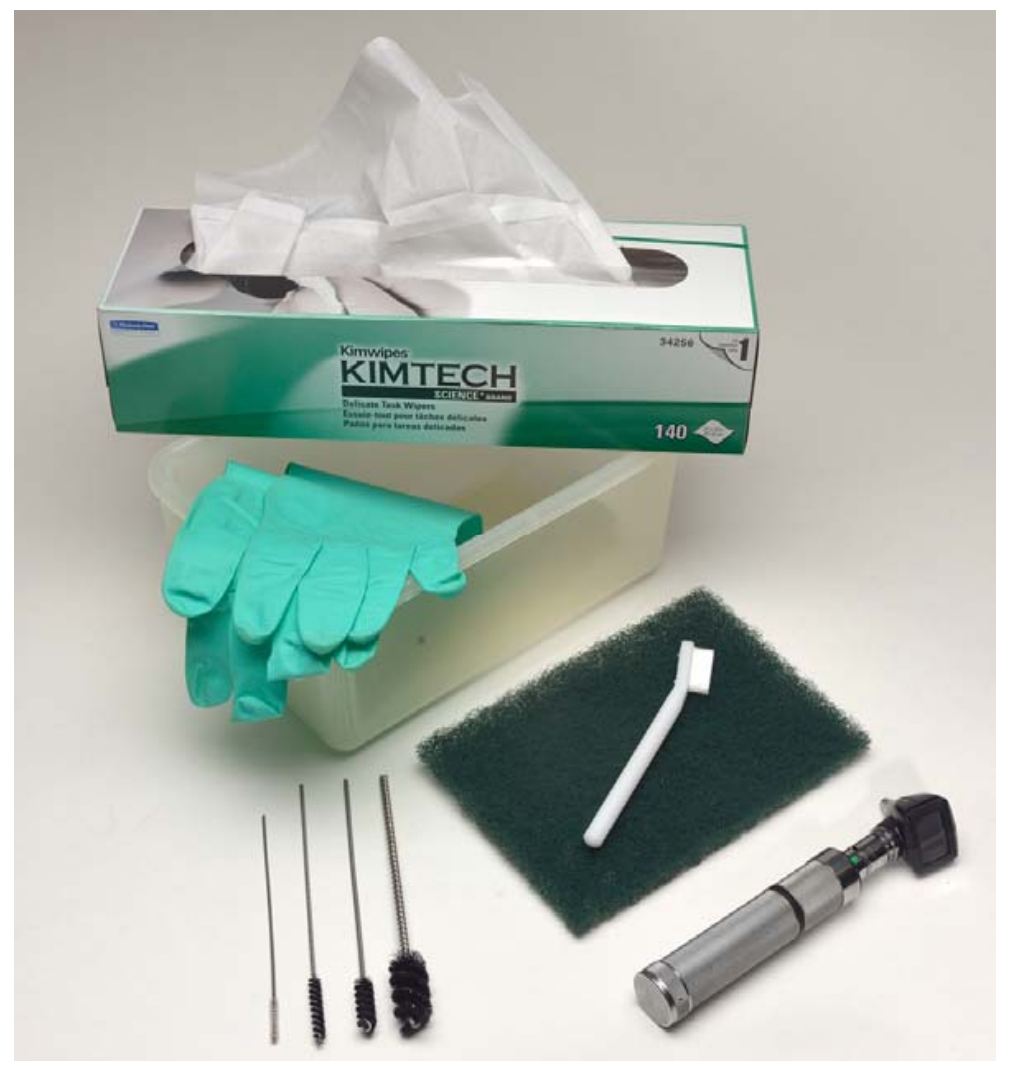




\section{Methodology (cont'd)}

- Environment

- Trial Group: SS sink, domestic hot water, table-top surface.

- Groups 1 - 3: SS work top in WSTF pre-clean room, which is a controlled shop environment with higher-than-normal air exchange, sticky mats at each entrance; smock is worn over street clothes.

- Each type of test article was uniformly contaminated.

- Identical recommended cleaning procedures were given to the three test groups. 


\section{Experimental Procedure}

- Test articles were verified to be at a similar level of cleanliness, and initial condition was noted.

- Test articles were contaminated according to a process (Table 3 ) so that they were all similarly soiled.

- The three individuals in each test group were provided with a set of identical cleaning supplies and a set of contaminated test articles. 
NASA NASA White Sands Test Facility

TABLE 3-Contamination process.

\begin{tabular}{|c|c|c|}
\hline Test Article & & Steps taken for Contamination of Test Articles \\
\hline \multirow{9}{*}{ Plates: } & & Initial condition: Shear-break edges, no special protection, visually similar \\
\hline & 1 & Fingerprints: Flip \& grip 10 times per each of 5 people \\
\hline & 2 & Lip balm: Smear on ( one long swipe on both sides near edge A) \\
\hline & 3 & Krytox $^{\circledR}$ lubricant: Dab \& smear ( one long swipe on both sides near edge B) \\
\hline & 4 & Lotion: Small dab \& smear (one long swipe on both sides near edge C) \\
\hline & 5 & Oil: 3 drops \& smear (one long swipe on both sides near edge D) \\
\hline & 6 & Metal powder: Dust (like salt) entire surface \\
\hline & 7 & Sand: Dust ( like salt) entire surface \\
\hline & 8 & Bag (unsealed) \\
\hline \multirow{6}{*}{$\begin{array}{c}\text { Oxygen } \\
\text { Bottle }\end{array}$} & & $\begin{array}{l}\text { Initial condition: As received from customer, uncapped, no gross } \\
\text { contamination, oil residue on threads. After first cleaning some rust was seen } \\
\text { in bottle }\end{array}$ \\
\hline & 1 & Krytox ${ }^{\circledR}$ lubricant: Small dab on threads, insert/remove fitting \\
\hline & 2 & Oil: 5 drops inside (from last thread to drip into bottle) \\
\hline & 3 & Metal powder: Drop 1 spatula of powder inside \& shake \\
\hline & 4 & Sand: Drop 1 spatula of sand inside and shake \\
\hline & 5 & Bag (unsealed) \\
\hline \multirow{8}{*}{ Valve } & & Initial condition: Cleaned 200A, opened, disassembled \\
\hline & 1 & Fingerprints: Flip \& grip 10 times per each of 5 people \\
\hline & 2 & Krytox ${ }^{\circledR}$ lubricant: Lube initial parts, reinsert and remove \\
\hline & 3 & Oil: 3 drops and shake \\
\hline & 4 & Metal powder: Drop $\sim 2 \mathrm{~mL}$ of powder inside and shake \\
\hline & 5 & Sand: Drop $\sim 2 \mathrm{~mL}$ of sand inside and shake \\
\hline & 6 & Teflon $^{\circledR}$ tape: Wrap threads with Teflon ${ }^{\circledR}$ tape, insert and remove fitting \\
\hline & 7 & Bag (unsealed) \\
\hline
\end{tabular}




\section{Experimental Procedure (cont'd)}

- Each person cleaned their three items following the recommended cleaning process and using only the supplied set of tools.

- Each individual's cleaned test articles were sampled using HFE 7100 by a WSTF clean room technician (not in a test group) to measure the amount of particulate and NVR. 


\section{Experimental Procedure (cont'd)}

- Sample Collection

- The verification process was performed in the WSTF preclean room using a $40-60$ psig $(0.3-0.4 \mathrm{mPa})$ rated pressure vessel with attached spray wand to rinse the components.

- A clean room technician rinsed each test article with $100 \mathrm{~mL}$ of HFE 7100 , which was then collected and filtered through a $0.45-\mu \mathrm{m}$ membrane filter.

- The membrane and the remaining HFE 7100 sample were sent to the WSTF Chem Lab for particle count and NVR analysis. 


\section{Experimental Procedure (cont'd)}

- Analysis of Data

- Each cleaned component was evaluated on a pass/fail basis for particulate cleanliness and NVR cleanliness, and compared against the target 300A criteria (JPR 5322.1G; Table 1).

- Both of these cleanliness parameters are adequate to reduce fire hazards in the subject oxygen system.

- Focus was on the quantitative analysis of cleanliness. The normal visual inspection pass/fail parameters for precision cleaning were not considered in this study.

- Performance of a test group was ranked by the rate of passing results (x parts of 9 per group).

- Passing $=$ achieving Level 300 


\section{Results and Discussion}

- Table 4 shows the level of cleanliness reached by each individual in each of the groups.

- Each of the groups achieved similar success rates (see Table 5).

- Outcome suggests that results are not dependent upon age, experience, technical training, or prior knowledge of oxygen hazards.

- Results indicate that the instructions were adequate to produce consistent results, and special training does not produce improved cleaning results. 


\section{Results and Discussion (cont'd)}

TABLE 4-Test results showing particulate and NVR levels achieved.

\begin{tabular}{ccccccc}
\hline \multirow{2}{*}{ Group } & \multicolumn{2}{c}{ Plate: } & \multicolumn{2}{c}{ Valve Body } & \multicolumn{2}{c}{ Oxygen Bottle } \\
\cline { 2 - 6 } & Particle & NVR & Particle & NVR & Particle & NVR \\
\hline Trial Group & $>300$ & $\mathrm{~B}$ & $>300$ & $\mathrm{~A}$ & 200 & $>\mathrm{D}$ \\
& 200 & $\mathrm{~A}$ & 100 & $\mathrm{~A}$ & $>300$ & $\mathrm{~A}$ \\
& 300 & $\mathrm{~A}$ & 200 & $\mathrm{~A}$ & $>300$ & $\mathrm{~A}$ \\
\hline Test Group 1 & $>300$ & $\mathrm{~A}$ & 200 & $\mathrm{~A}$ & 300 & $\mathrm{~A}$ \\
& $>300$ & $\mathrm{~A}$ & $>300$ & $\mathrm{~A}$ & $>300$ & $>\mathrm{D}$ \\
& $>300$ & $\mathrm{~A}$ & $>300$ & $\mathrm{~A}$ & 300 & $\mathrm{~A}$ \\
\hline Test Group 2 & $>300$ & $\mathrm{~A}$ & $>300$ & $\mathrm{~A}$ & 300 & $\mathrm{~A}$ \\
& $>300$ & $\mathrm{~A}$ & 300 & $\mathrm{~A}$ & $>300$ & $\mathrm{~A}$ \\
& $>300$ & $\mathrm{~A}$ & $>300$ & $\mathrm{~A}$ & 300 & $\mathrm{~A}$ \\
\hline Test Group 3 & $>300$ & $\mathrm{~A}$ & 300 & $\mathrm{~A}$ & $>300$ & $\mathrm{~A}$ \\
& 200 & $\mathrm{~A}$ & $>300$ & $\mathrm{~A}$ & $>300$ & $\mathrm{~A}$ \\
& 300 & $\mathrm{~A}$ & $>300$ & $\mathrm{~A}$ & $>300$ & $\mathrm{~B}$ \\
\hline
\end{tabular}




\section{Results and Discussion (cont'd)}

TABLE 5-Percentage of parameters passed to achieve Level 300A cleanliness.

\begin{tabular}{|c|c|c|c|c|c|c|c|}
\hline \multirow[t]{2}{*}{ Group } & \multicolumn{2}{|c|}{ Plate } & \multicolumn{2}{|c|}{ Valve Body } & \multicolumn{2}{|c|}{ Oxygen Bottle } & \multirow{2}{*}{$\begin{array}{l}\text { Group } \\
\text { Ratio }\end{array}$} \\
\hline & Particle & NVR & Particle & NVR & Particle & NVR & \\
\hline $\begin{array}{l}\text { Trial Group } \\
\text { (Engineers) }\end{array}$ & $66 . \overline{6} \%$ & $66 . \overline{6} \%$ & $66 . \overline{6} \%$ & $100 \%$ & $33 . \overline{3} \%$ & $66 . \overline{6} \%$ & $66 . \overline{6} \%$ \\
\hline $\begin{array}{l}\text { Test Group } 1 \\
\text { (Cleaning technicians) }\end{array}$ & $0 \%$ & $100 \%$ & $33 . \overline{3} \%$ & $100 \%$ & $66 . \overline{6} \%$ & $66 . \overline{6} \%$ & $61 . \overline{1} \%$ \\
\hline $\begin{array}{l}\text { Test Group } 2 \\
\text { (Co-op Students) }\end{array}$ & $0 \%$ & $100 \%$ & $33 . \overline{3} \%$ & $100 \%$ & $66 . \overline{6} \%$ & $100 \%$ & $66 . \overline{6} \%$ \\
\hline $\begin{array}{l}\text { Test Group } 3 \\
\text { (Engineers) }\end{array}$ & $66 . \overline{6} \%$ & $100 \%$ & $33 . \overline{3} \%$ & $100 \%$ & $0 \%$ & $66 . \overline{6} \%$ & $61 . \overline{1} \%$ \\
\hline All Groups: & $33 . \overline{3} \%$ & $91 . \overline{6} \%$ & $41 . \overline{6} \%$ & $100 \%$ & $41 . \overline{6} \%$ & $75 \%$ & -- \\
\hline Test Groups only: & $22 . \overline{2} \%$ & $100 \%$ & $33 . \overline{3} \%$ & $100 \%$ & $44 . \overline{4} \%$ & $77 . \overline{7} \%$ & -- \\
\hline
\end{tabular}




\section{Results and Discussion (cont'd)}

- NVR levels were met much more frequently than particulate levels.

- 93\% NVR samples passed Level 300, vs. 33\% particulate samples.

- Consistency between the test groups indicates that efficacy of the procedure is relatively independent of prior knowledge of oxygen hazards, cleaning experience, and education.

- The implication is that it is much easier to remove the NVR (e.g., oil, lip balm, lubricant, fingerprints) than to remove particulate contaminant (e.g., particles and fibers). 


\section{Results and Discussion (cont'd)}

- The oxygen bottle was the most difficult item from which to remove the NVR.

- Special training emphasis should be placed on how to clean the inside of the bottle.

- Vessels showed signs of rust after cleaning by all test groups (including the Trial Group). The rust would have been mitigated in a standard precision cleaning process in order to pass visual inspection.

- Used because of its availability, HFE 7100 is not as aggressive as $\mathrm{AK} 225^{\circledR}$, normally used to validate a cleaning process. 


\section{Results and Discussion (cont'd)}

- The possible lack of control of particulate contamination and the presence of rust increase the possibility of a particle impact ignition mechanism being present.

- An evaluation of the possibility of particle impact ignition in the subject oxygen system was recommended.

- The rudimentary cleaning process tested could be used to maintain oxygen systems if it were determined that the particles were too few or too small to create a credible fire hazard. 


\section{Conclusion}

- With proper cleaning procedures that incorporate contamination control principles, a cleanliness level of $300 \mathrm{~A}$ is possible to quantitatively achieve in a field shop environment.

- The consistency of cleanliness parameters met cannot compare to those achieved in a precision cleaning facility,

- With the joint understanding of oxygen and contamination control, one can determine if such field cleaning can meet the requirements to maintain a safe oxygen system. 


\section{References}

- ASTM G93. Standard Practice for Cleaning Methods and Cleanliness Levels for Material and Equipment Used in Oxygen-Enriched Environments. ASTM International, West Conshohocken, PA, 2003.

- NASA JPR5322.1G. Contamination Control Requirements Manual. NASA Johnson Space Center Procedural Requirements. Houston, TX, 2009.

- ASTM F312. Standard Test Methods for Microscopical Sizing and Counting Particles from Aerospace Fluids on Membrane Filters. ASTM International, West Conshohocken, PA, 2008.

- ASTM F331. Standard Test Method for Nonvolatile Residue of Solvent Extract from Aerospace Components (Using Flash Evaporator). ASTM International, West Conshohocken, PA, 2005. 


\section{Recommended Rudimentary Procedures}

Equipment

Water-

Pans-

Brushes-

Soap-

Gloves-

Rags-

Inspection

Tools-

Work Surface and Washing Station-
Hot DI water, with a high pressure wand or nozzle. If DI water is not available, use the cleanest available water supply.

Note: In all cases, warmer and cleaner water is better. If gloves can be worn to enable the water temperature to be higher, that is a favorable practice. Warm or hot water cuts grease and dissolves oil deposits far better than cool or cold water.

Metal pans to contain cleaning solutions and rinse water. If metal pans are not available, plastic pans may be used.

Clean brushes in a variety of sizes and shapes to fit small crevices and reach all ends (e.g., spiral brush, end brush, bottle brushes, toothbrush-style brush), nonmetallic scouring pads.

Warning: Ensure that the brushes will not damage the hardware to be cleaned. Warning: Do not use metallic scouring pads because they shed particles that can either rust or become imbedded in softer materials, or both.

Note: Brush or tool extensions can be fabricated, if necessary, to enable physical scrubbing of parts that are otherwise inaccessible.

Soap with no moisturizers or scents added (e.g., Simple Green). If unavailable, use dish soap.

Nylon or Nitrilite gloves that tend not to shed particulate. If non-shedding gloves are not available, use rubber gloves.

Lint free cloth or paper wipes (e.g., Kimwipes), cotton cloth.

Magnifying glass, flashlight, otoscope (can be used for looking inside vessels and components), fluorescent lamp with magnifying glass, bright light source.

Work surface and washing station that are located near one another. Metal surface that can be wiped clean or a visually clean plastic or paper sheet to cover work surface.

Note: The work surface will be used to locate items that must be kept clean during the process such as clean brushes, wipes, bags, and gloves, as well as provide a location that clean items can be located while preparing for bagging after the cleaning process is complete. Finally, the work surface will be used for disassembly and re-assembly of components. 


\begin{tabular}{|c|c|}
\hline \multicolumn{2}{|c|}{ General Procedure } \\
\hline $\begin{array}{l}\text { Prepare } \\
\text { Workplace-- }\end{array}$ & $\begin{array}{l}\text { Choose a work area that is somewhat controlled to avoid open access and to } \\
\text { minimize contamination. Get all supplies and tools together before beginning } \\
\text { the cleaning process to avoid delays once the cleaning process is underway. }\end{array}$ \\
\hline & $\begin{array}{l}\text { Wipe down the metal work surface or place a clean plastic sheet or clean paper } \\
\text { on the work surface. } \\
\text { Ensure that the work surface remains visually clean during the } \\
\text { disassembly and cleaning processes. } \\
\text { - If necessary, wipe down the work surface to ensure that } \\
\text { contamination from one item does not get transferred to other } \\
\text { items. }\end{array}$ \\
\hline & $\begin{array}{l}\text { Set up a series of wash/rinse pans. } \\
\qquad \quad \text { Wash pans should progress from less to more clean. } \\
\text { - For example, the first pan might contain hot, soapy water for pre- } \\
\text { cleaning and soaking dirtier items. The second pan might contain } \\
\text { hot, soapy water for scrubbing cleaner items. The third pan might } \\
\text { be for initial rinsing, and the fourth pan might contain clean, hot } \\
\text { water for final rinsing. } \\
\text { - Change out the water in each pan as required when it becomes } \\
\text { dirty. }\end{array}$ \\
\hline Disassemble- & $\begin{array}{l}\text { Completely disassemble the component so that all crevices and internal surfaces } \\
\text { are as accessible as possible. } \\
\text { Note: Each part must be cleaned separately, in a disassembled configuration. If } \\
\text { they are not, the effectiveness of the cleaning procedure will be significantly } \\
\text { reduced. Parts that are not removed provide crevices and cracks that will retain } \\
\text { contaminants and it will not be possible to clean the adjoining surfaces of the } \\
\text { parts. }\end{array}$ \\
\hline Pre-clean- & $\begin{array}{l}\text { Remove excessive contamination. } \\
\qquad \quad \text { Wipe the component. } \\
\bullet \quad \text { Discard the soiled wipes. } \\
\bullet \quad \text { Continue this process until as much visible contamination is } \\
\text { removed as possible. }\end{array}$ \\
\hline
\end{tabular}


Wash- Soak item in hot (the hotter, the better) soapy water as needed to loosen contaminant from surfaces.

- If item is a tank or a bottle, fill it with soapy water until it is overflowing, then let it soak.

Scrub/agitate the part thoroughly.

- Use brushes, wetted Kimwipes, or cotton cloth.

- Pay special attention to threads, crevices, and hidden surfaces that, because of their configuration, can trap contaminants.

- If internal surfaces cannot be scrubbed mechanically, then spray the inaccessible areas. If scrubbing or spraying are not possible, fill the item with hot, soapy water, plug the holes, and shake it vigorously.

Note: Ensure that many suds are formed during the washing process; if there are few suds, then add more water and soap. If suds don't form, it indicates that all the oil contamination is not captured by the surfactant.

- Change the wash water, add soap, and repeat the washing process twice for a total of three washes.

Note: This procedure amounts to very rigorous dishwashing with very careful attention given to detail and precision. The hotter and soapier the water the better. The repetitions ensure that the surface is thoroughly cleaned and that layered contamination is wetted, agitated, and removed.

Rinse- $\quad$ Rinse item thoroughly to remove soap and contaminant.

- Dunk and spray item with clean hot water as needed to remove all visible residues.

- If item is a bottle, then fill, shake, and empty the water until no suds are left and the water coming out is as clear as water going in.

Note: Gloves should be rinsed often to remove contaminants and particles obtained by touching contaminated parts. If a particle can be transferred to a cleaned part by physical contact, it is very likely that it can be rinsed off. Rinse it off prior to touching the parts.

Inspect rinse water.

- Catch the last rinse water in clear container.

- Look for particles or grease in the water using a magnifying glass and by shining a bright white light through the water

- If no particles are present or grease is observed on the surface (as a colorful sheen) and the water is as clear as it was from the source, move on to drying; if not, repeat the wash and rinse steps.

Note: When washing carbon steel components like the oxygen bottles, perform the final rinse with cold water and then dry immediately. The combined effects of cooling the carbon steel surface and drying it quickly will inhibit as much as possible the formation of rust. 


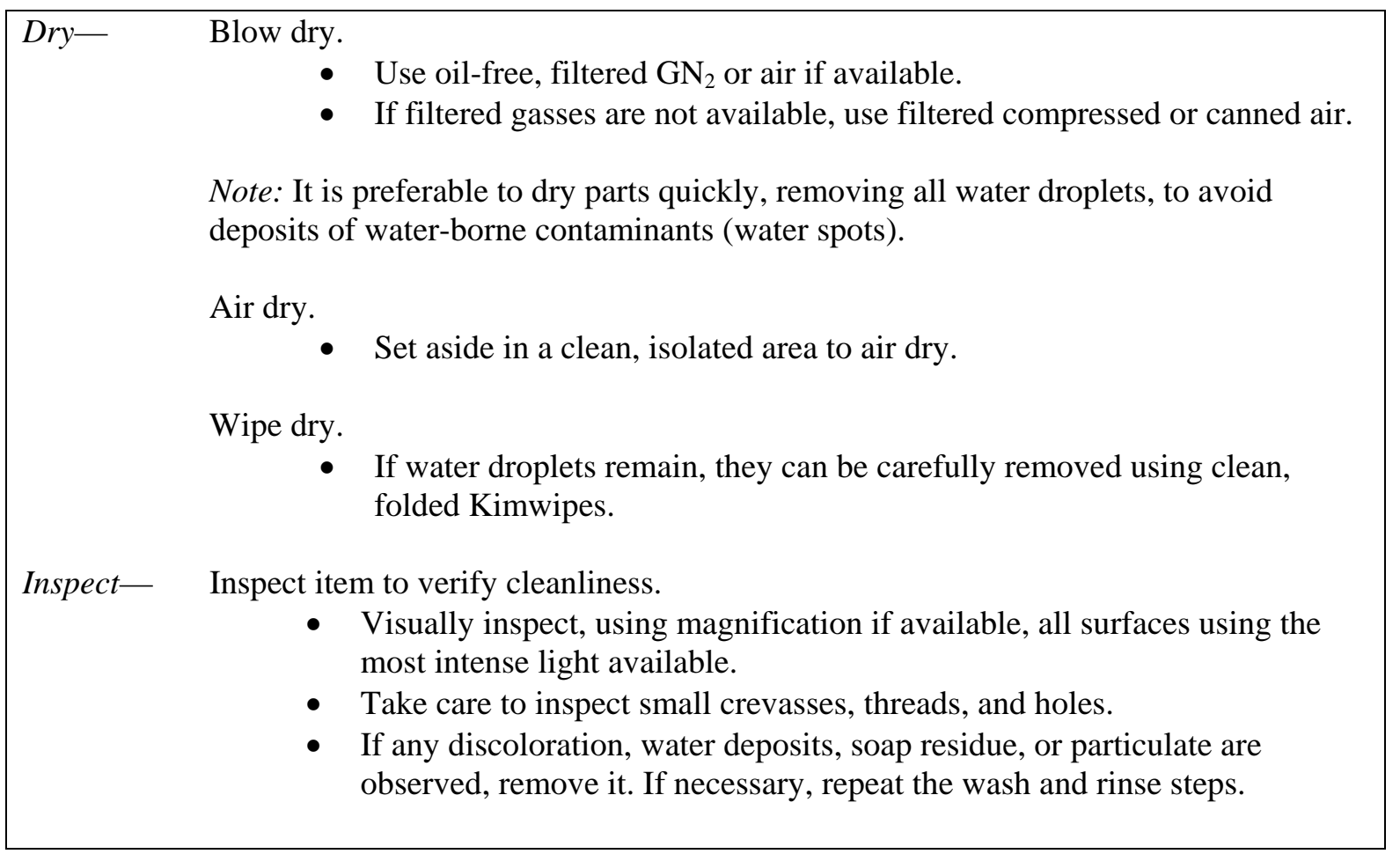

